\section{West Nile rates soar in 2007}

$\mathrm{E}$ rstwhile hopes that the West Nile Virus may have been slowly disappearing in Canada dissipated this season as the country experienced the largest outbreak since the virus' arrival in 200I.

A staggering 2260 human clinical cases were reported to the Public Health Agency of Canada as of Oct. 20, a startling jump from I5I confirmed cases in 2006. That increase was most pronounced in Saskatchewan, where the number of cases rose to 1359 from I9 in 2006, and in Manitoba, where cases rose to 559 from 50 (Table I).

Manitoba leads the nation in the number of cases (46) of the most severe form of the disease, West Nile Neurological Syndrome, in which permanent neurological damage is caused to the brain. Saskatchewan recorded 40 cases, Alberta I9, British Columbia 8, Quebec $\mathrm{I}$ and Ontario I.

City of Winnipeg entomologist Taz Stuart says the outbreak in Manitoba was largely a function of environmental conditions, which "were very suitable for an outbreak of the Culex tarsalas mosquitoes. In May and June, we had a large amount of rain, which produced a habitat for the first generation. The hot weather that followed provided conditions for lots of eggs."

Stuart also said that increased media attention resulted in a higher number of people being tested, which may have contributed to the increases in Manitoba. But Dr. Michael Drebot, head of Health Canada's Viral Zoonoses Section, says the high incidence of 2007 "stems more from the ecological factors such as climate and the high number of infected Culex tarsalas."

Stuart and Drebot also indicated that the 2007 increases are not necessarily an indicator of future incidence. While more accurate predictive models are being sought, using accumulated data, none are completed, or foolproof. "We hope to provide these models and possibly, risk indices to be more accurate," Stuart says. But it's a challenge because "each year is unique in itself."

"The message is that every season holds the potential for a large epidemic. People need to take precautions even if there are not swarms of mosquitoes around; the few that are around may be infected with the virus," warns Drebot. "People cannot be lulled into a false sense of security." - Shawna Lessard, Ottawa, Ont.

DOI:Io.I503/cmaj.071566

Table 1: Number of human cases of West Nile virus infection in Canada, 2002-2007

\begin{tabular}{|c|c|c|c|c|c|c|}
\hline \multirow[b]{2}{*}{ Province/territory } & \multicolumn{6}{|c|}{ No. of reported cases } \\
\hline & 2002 & 2003 & 2004 & 2005 & 2006 & $2007^{*}$ \\
\hline \multicolumn{7}{|c|}{ Newfoundland and Labrador } \\
\hline Prince Edward Island & & & & 1 & & \\
\hline Nova Scotia & & 2 & & 1 & & \\
\hline New Brunswick & & 1 & & 1 & & \\
\hline Quebec & 20 & 17 & $3 \dagger$ & 4 & 1 & 1 \\
\hline Ontario & $394 \dagger$ & 89† & $13 \dagger$ & $95 \dagger$ & $42 \dagger$ & 12 \\
\hline Manitoba & & $142 \dagger$ & 3 & 55 & 50 & 559 \\
\hline Saskatchewan & & $937 \dagger$ & $5 \dagger$ & $58 \dagger$ & $19+$ & 1359 \\
\hline Alberta & & $272 \dagger$ & 1 & $10 \dagger$ & $39 \dagger$ & 311 \\
\hline British Columbia & & 20 & & & & 18 \\
\hline Yukon Territory & & 1 & & & & \\
\hline \multicolumn{7}{|l|}{ Northwest Territories } \\
\hline \multicolumn{7}{|l|}{ Nunavut } \\
\hline Total & 414 & 1481 & 25 & 225 & 151 & 2260 \\
\hline
\end{tabular}

\section{Gairdner winners honoured}

\section{at Toronto symposium}

A dvances in combating cancer and promising avenues of research highlighted the lectures of 5 newly minted Gairdner International Award winners at a University of Toronto symposium Oct. 25-26.

The culmination of a nation-wide lecture series, the symposium also featured a dozen addresses by past Gairdner winners around the themes of "Advances in the Treatment of Cancer" and "Advances in Our Understanding of Cancer." Established in 1959 by Toronto businessman James Gairdner, the awards aim to recognize research that improves the quality of life.

The 5 new winners, each of whom received \$30 000 and a La Coeur statue, sketched the research that underpinned their careers and their thoughts on where their fields are headed. The 2007 recipients:

\section{David Allis: "K" for cancer}

Honoured for his work in cancer epigenetics, the head of the Laboratory of Chromatin Biology at Rockefeller University in New York City, New York, said in his lecture that he was struck by the concept of identical twins having the same DNA, yet only I with autism. That notion, to Allis, seemed a powerful demonstration that DNA cannot explain all changes in gene function.

The theoretical pair of twins demonstrates that genes can remain unchanged, but suddenly "switch off" when they should remain active. Epigenetics, Allis's specialty, aims to determine how to turn these genes back on.

Allis discovered a " $\mathrm{K}$ " marker that may be a cancer switch inside histone tails in DNA sequences. Based on that discovery, a Sloan-Kettering study applied drugs to a lung cancer patient and discovered that his tumours hollowed out after 8 weeks of treatment ( $\mathrm{Clin}$ Oncol 2005;23[17]:3923-3I).

Kim Nasmyth: Chromosome tug-of-war Cited for decoding the mechanics of cell division, the Whitley Chair holder at the Department of Biochemistry at Oxford University in England spoke of 


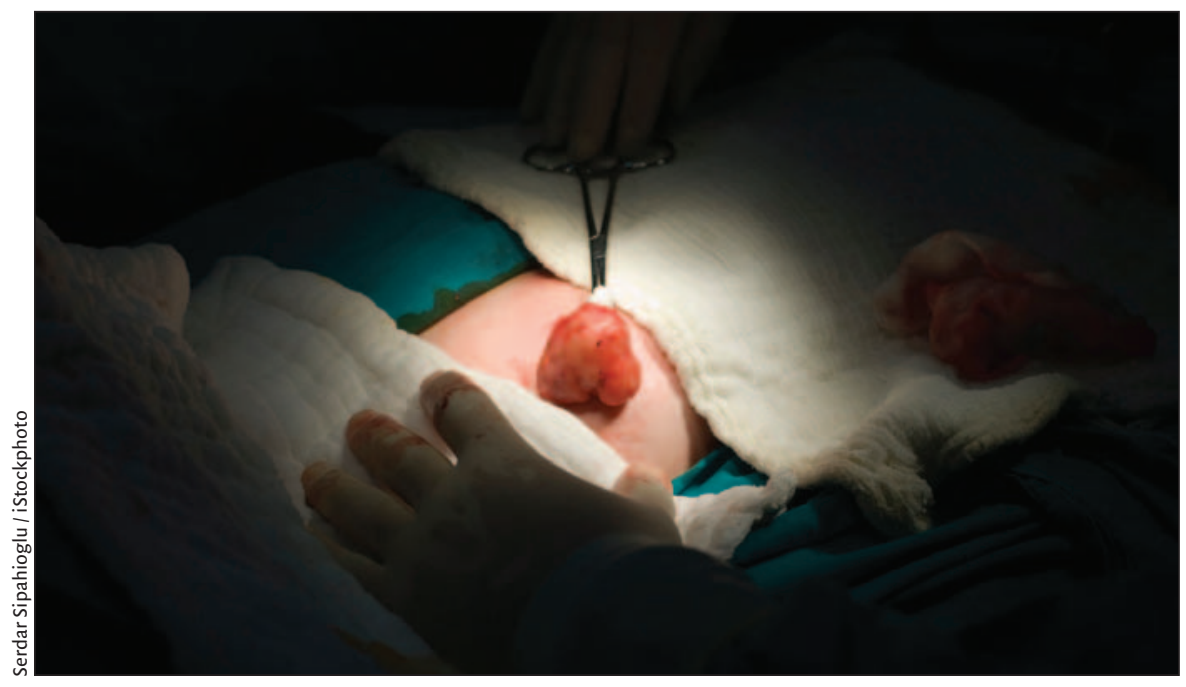

Less invasive cancer tumour treatments was one of the topics tackled at the 2007 Gairdner Foundation lectures.

his team's efforts to track DNA during separation.

A cell must line up all 46 chromosomes in its nucleus before separating. An enzyme called cohesion holds the chromosome pairs inside a protein ring until the moment when they are all aligned and another enzyme, dubbed separase, kicks in. Intrigued by how DNA got inside the cohesion ring, Nasmyth found that the cell twists open a hinge on I side of the ring to allow the DNA to enter.

Cohesion also seems to have other uses besides cell division. A lack of cohesion has been traced to Cornelia de Lange Syndrome, which affects child development, Nasmyth said.

\section{Harry Noller: X-rays mark the spot} Awarded for his pioneering work in $\mathrm{x}$-ray imaging, the director of the Center for Molecular Biology of RNA at the University of California, Santa Cruz, California, used animation to illustrate his efforts to map ribosome structure.

A mass of what appears as unraveled, tangled videotape sits inside our cells. Noller's team mapped that enzyme, called a ribosome, to unprecedented detail using $\mathrm{x}$-rays, in hopes of understanding how it decodes RNA nucleic acids that are associated with the cell's chemical activities.

Noller said the ribosome moves in concert with the movements of RNA through its massive structure. The team hopes to completely map the process.

\section{Thomas Steitz: Drugs target the spot}

Building on advances in the knowledge of ribosome structure, the professor at the Department of Molecular Biophysics and Biochemistry, Howard Hughes Medical Institute at Yale University in New Haven, Connecticut, outlined how awareness of the process can help in the design of less resistant antibiotics.

A class of antibiotics called macrolides, for example, bonds in a peptide tunnel inside the ribosome, Steitz said. Different families of antibiotics bind to different areas in the ribosome. Thus, a researcher can take a piece of I antibiotic, bond it to a piece of another, and make a hybrid that binds to the ribosome more tightly and combats antibiotic resistance.

\section{Dennis Slamon: Different breasts, dif- ferent cancers}

Sketching advances in breast cancer research, the professor of the Department of Medicine at the University of California at Los Angeles said it was once believed all breast cancers were of similar composition and should receive similar treatments. But research indicates that more molecular information about cancer should lead to more effective - and less invasive - therapy for patients, Dr. Slamon said.

Slamon was honoured for discover- ing, in 1989 , that $20 \%$ to $25 \%$ of breast cancers have an overactive hormone called HER2. He targeted the hormone using herceptin, in combination with chemotherapy, and found it improved the survival rate of cancer patients in the first year after therapy.

\section{Burning up tumours}

Among the addresses from former Gairdner recipients and other prominent medical researchers was I from Tak Mak, the director of the Campbell Family Institute for Breast Cancer Research and Senior Scientist at the Division of Stem Cell and Development Biology, Advanced Medical Discovery Institute/Ontario Cancer Institute. It tackled the socalled oncogene revolution.

Mak argued that the revolution set back clinical oncology. In 1976, he said, researchers had a dream: to cure cancer by blocking oncogenes. Some inhibitors have been in trials for more than a decade, but with limited success, he said.

Instead, Mak suggested targeting metabolism as the basis for a new anticancer strategy and cited his recent work using diachloroacetate in mice, which appears to suppress tumour growth (Science STKE, Io April 2007, p. per4) - Elizabeth Howell, CMAJ

DOI:I0.1503/cmaj.071597

\section{News @a glance}

Ratatouille: Lab rats. Peons. Minions. Grad students. Postdocs. The time has come to finally eliminate the interchangeability of such labels within British universities, says the UK Council for Science and Technology. Calling for a major overhaul of the way universities treat "lost souls" otherwise known as young researchers, the nation's chief science advisory body has urged such radical reforms as wider use of research fellowships and setting aside more monies at research councils for fellowship programs to prevent the next generation of scientists from having to first serve as slave labour for the ruling research gerontocracy. "Giving an early-career researcher the opportunity to apply for even small sums of funding at an early stage gives them valu- 